\section{Vozes e modalizações em competências da matriz de avaliação e em redações nota mil do Exame Nacional do Ensino Médio - ENEM}

Speeches and modalizations in competences of the evaluation matrix in essays that reached the maximmum grade of the National Secondary School Exam - ENEM

Aymmée Silveira SANTOS (UFPB) aymmeesst@gmail.com

Recebido em: 06 de ago. de 2018. Aceito em: 21 de dez. de 2019.
SANTOS, Aymmée Silveira. Vozes e modalizações em competências da matriz de avaliação e em redações nota mil do Exame Nacional do Ensino Médio - ENEM. Entrepalavras, Fortaleza, v. 9, n. 1, p. 112-130, jan$\mathrm{abr} / 2019$.

Resumo: Os postulados do Interacionismo Sociodiscursivo definem que o texto, materialidade empírica das interações verbais inerentes ao meio social, é organizado por três camadas superpostas: a infra-estrutura geral do texto, os mecanismos de textualização e os mecanismos enunciativos. Considerando que os mecanismos enunciativos demonstram contribuir para a manutenção da coerência pragmática do texto, através do esclarecimento de posicionamentos enunciativos e de diversas avaliações sobre alguns aspectos do conteúdo temático do texto, o presente artigo tem como objetivos: i) Identificar em competências da matriz de avaliação do Exame Nacional do Ensino Médio (Enem) direcionamentos que apontam para a necessidade de utilização de mecanismos enunciativos, ii) Ressaltar a relevância dos mecanismos enunciativos para a elaboração de um texto dissertativo-argumentativo que atenda aos critérios de correção estabelecidos pelo Enem, através da verificação de vozes e modalizações em algumas redações que obtiveram nota máxima no Exame e, iii) Descrever a importância da utilização dos mecanismos enunciativos para a construção de textos argumentativos 
consistentes e convincentes. Através dos postulados teóricos de Bronckart (1999; 2006), Habermas (1989) etc, o trabalho teve como procedimentos metodológicos a análise de competências da matriz de avaliação do Enem e de redações que obtiveram nota máxima no Enem 2017, buscando evidenciar a sua associação com os mecanismos. Os resultados obtidos demonstraram que o gerenciamento das vozes enunciativas funciona como estratégias argumentativas, e a predominância das modalizações pragmáticas nas propostas de intervenção, presentes nas redações está associada ao caráter propositivo inerente a esta seção, exigido pelo Enem.

Palavras-chave: Redações dissertativo-argumentativas do Enem. Mecanismos enunciativos. Interacionismo Sociodiscursivo.

Resumo: The postulates of Sociodiscursivo Interacionismo define that the text, empirical materiality of the verbal interactions inherent to the social environment, is organized by three parts: the general infrastructure of the text, the mechanisms of textualization and the enunciative mechanisms. Considering the enunciative mechanisms which demonstrate the contribution of the pragmatic coherence of the text, through theenlightening of enunciative positions and various evaluations on some aspects of the thematic content of the text, this article aims to: i) to identify in the competencies of the rule matrix of the Enem - A Brazilian exam for the superior education access - directives which point to the need to use enunciative mechanisms; ii) to emphasize the relevance of enunciative mechanisms for the elaboration of an argumentative essay that meets the criteria of correction established by the Enem exam, through verification of speeches and modalizations in some essays that obtained a maximum mark in the Exam and, iii) to describe the importance of the use of enunciative mechanisms for construction of consistent and convincing argumentative texts. Based on the work of authors such as Bronckart $(1999,2006)$, Habermas (1989)etc, this work had, as methodological procedures, the competency analysis of the evaluation matrix from the Enem's directives and of essays that obtained maximum scores in the Enem 2017 edition, trying to evidence the association with the mechanisms. Results showed that the management of enunciative voices functions work as argumentative strategies and the predominance of the pragmatic modifications in the intervention proposals present in the essays is associated with the propositional character inherent to that section, demanded by the Enem.

Keywords: Enem's argumentative-essays. Enunciative mechanisms. Sociodiscursive Interactionism.

\section{Introdução}

A vertente de estudo interacionista sociodiscursiva (ISD) elucida o fato de que a língua (oral e escrita) é uma prática social, e os gêneros textuais são um instrumento de interação que auxiliam a comunicação, pois permitem a materialização das práticas de linguagem de um meio social, carregando consigo a pluralidade de vozes que sustentam o discurso como realidade. Nesta perspectiva, os mecanismos enunciativos, constituídos como uma das camadas da organização interna de um texto empírico (BRONCKART, 1999; 2006), demonstram contribuir para a manutenção da coerência pragmática do texto, através do esclarecimento de posicionamentos enunciativos e de diversas avaliações sobre alguns aspectos do conteúdo temático do texto. 
V. 9 (1) $112-130$ jan-abr 2019
Estes aspectos refletem a essência dialógica discursiva apontada por Bakhtin (2006) ao considerar que todo texto é polifônico, e enfatiza que a partir de qualquer voz enunciativa, podem ser formuladas avaliações através do uso de modalizações, funcionando, consequentemente, como recursos linguísticos facilitadores de estratégias argumentativas.

Levando em conta que o Exame Nacional do Ensino Médio (Enem) é, atualmente, o principal método de ingresso nas instituições de Ensino Superior, cuja prova consiste, dentre outras questões, na elaboração de um texto dissertativo-argumentativo, como uma das maneiras de avaliar as habilidades e competências dos candidatos, julgamos oportuno responder ao seguinte questionamento: De que modo os mecanismos enunciativos se comportam como recursos indispensáveis para a elaboração de estratégias argumentativas consistentes e convincentes ao leitor (avaliador) da produção textual dissertativo-argumentativa do Enem?

Assim, o presente artigo tem como objetivo geral analisar a correlação dos mecanismos enunciativos (vozes e modalizações) e a proposta de produção textual do Enem, apontando sua relevância para a elaboração de uma redação dissertativo-argumentativa satisfatória, com base na identificação de direcionamentos destes mecanismos em competências da matriz deavaliação do Exame ena verificação da presença de vozes e modalizações em algumas produções textuais de 2017 que obtiveram nota máxima. Desdobram-se, portanto, os seguintes objetivos específicos: i) Identificar em competências da matriz de avaliação do Enem direcionamentos que apontam para a necessidade de utilização de mecanismos enunciativos, ii) Ressaltar a relevância dos mecanismos enunciativos para a elaboração de um texto dissertativo-argumentativo que atenda aos critérios de correção estabelecidos pelo Enem, através da verificação de vozes e modalizações em algumas redações de 2017 que obtiveram nota máxima, e iii) Descrever a importância da utilização dos mecanismos enunciativos para a construção de textos argumentativos consistentes e convincentes.

Para isso, utilizaremos como aportes teóricos estudos desenvolvidos pelo Interacionismo Sociodiscursivo (ISD), como os de Bronckart (1999; 2006); Habermas (1989) e Marcuschi (2009). Como procedimentos metodológicos, serão analisadas as competências ${ }^{1} 2$, 3 e 5 da matriz de avaliação do Enem, presente na Cartilha do Participante

${ }^{1}$ Optamos por não analisar as competências 1 e 4 por estarem associadas à organização geral do texto, distanciando dos nossos objetivos de pesquisa. 
de 2017, buscando evidenciar a sua associação com os mecanismos enunciativos. Também, serão selecionadas quatro redações que obtiveram nota máxima no Enem 2017, com o intuito de verificarmos a presença de vozes e modalizações como recursos linguísticos indispensáveis para o atendimento da proposta de produção textual dissertativa-argumentativa e dos critérios de avaliação do Exame.

\section{Os gêneros textuais enquanto práticas sociais: alguns pressupostos do Interacionismo Sociodiscursivo (ISD)}

Um dos basilares dos estudos voltados para o Interacionismo Sociodiscursivo (ISD) é o fato de que o ser humano é um ser essencialmente social, pois é criado e existe nas relações sociais. Conforme asseverou Vygotsky (1984), em seus estudos, os processos de significação acontecem sob o amálgama entre homem e sociedade, e a própria linguagem é definida como uma atividade. Em decorrência disto, a dinâmica do funcionamento dos aspectos da vida social afeta a linguagem e esta exerce influência estabilizadora e/ou modificadora nessa dinâmica (FARACO, 2007).

De acordo com Habermas (1989), o agir comunicativo, caracterizado pela cooperação dos indivíduos na atividade de linguagem, através da regulação e mediação de interações verbais, se materializa na entidade empírica que é o texto. Nesse sentido, a produção de um texto é compreendida como uma atividade processual que, dialogicamente, mobiliza as representações de mundo propostas pelo estudioso: o mundo objetivo, que corresponde ao que é verdadeiro, real; o mundo social, atravessado pelo compartilhamento e aceitação das regras sociais, decorrentes da avaliação das pretensões de legitimidade dessas convenções e normas sociais, e o mundo subjetivo, que engloba as representações individuais sobre o pensamento coletivo, sendo avaliadas as pretensões de veracidade.

É neste cenário sociointeracionista que surge a relevância dos gêneros textuais enquanto ações que relacionam homem, língua e discurso, de acordo com as verdades do grupo social, na rede simbólica que dimensiona e ampara crenças e valores (MARCUSCHI, 2009). Para Bakhtin (2006), os gêneros são tipos de enunciado relativamente estáveis, que representam o efetivo funcionamento da linguagem verbal como reflexo da interação humana. São uma prática de linguagem historicamente constituída, cristalizada e reconstruída de forma progressiva no curso da história. 
V. 9 (1)

$112-130$

jan-abr

2019

Ao funcionarem como reflexos das práticas sociais nos mais variados campos da atividade humana, os gêneros são, antes de tudo, um instrumento de interação que auxilia a comunicação, ao materializar as práticas de linguagem de um meio social, e carregam consigo a pluralidade de vozes que sustentam o discurso como realidade. Como salienta Marcuschi (2010), "quando dominamos um gênero textual, não dominamos uma forma linguística e sim uma forma de realizar linguisticamente objetivos específicos em situações sociais particulares". Assim, ao trazerem consigo uma expressividade típica, influenciada pela esfera de circulação que o difunde (FIORIN, 2006), os gêneros devem ser compreendidos como entidades discursivo-pragmáticas que auxiliam o aprimoramento da competência comunicativa, levando os sujeitos (agentes) a refletirem sobre a linguagem verbal como prática social.

\section{Os mecanismos enunciativos: vozes e modalizações}

A organização interna de um texto empírico é concebida por Bronckart (1999; 2006) como um folhado constituído por três camadas superpostas: a infra-estrutura geral do texto, os mecanismos de textualização e os mecanismos enunciativos, conforme é demonstrado na figura, a seguir:

Figura 01 - O folhado textual

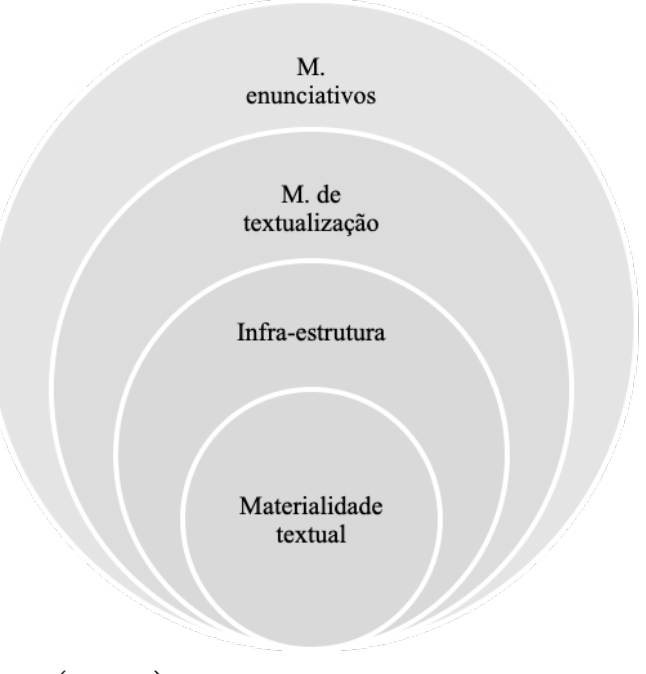

Fonte: Bronckart (1999).

De modo geral, a infraestrutura geral é caracterizada pelo plano geral do texto, determinado pela organização temática, pela combinatória específica dos tipos de discurso, das sequências e de outras formas de planificação presentes no texto. Por sua vez, os mecanismos 
de textualização correspondem às regras de organização geral do texto, compreendendo a coesão nominal e os mecanismos de conexão. Os mecanismos enunciativos, que serão analisados mais detidamente neste artigo, referem-se à evidenciação dos posicionamentos enunciativos, bem como à explicitação das modalizações (BRONCKART, 1999; 2006).

Segundo Bronckart (1999; 2006), os mecanismos enunciativos visam orientar a interpretação do texto de seus destinatários, contribuindo para a manutenção da coerência pragmática do texto, através do esclarecimento de posicionamentos enunciativos e de diversas avaliações (julgamentos, opiniões, sentimentos) sobre alguns aspectos do conteúdo temático.

Para o estudioso, um texto é polifônico quando nele se fazem ouvir vozes distintas. Podendo estar implícitas no texto ou explicitadas por formas pronominais, sintagmas nominais, ou por frases ou segmentos de frases, as vozes são pertencentes a três subconjuntos: a voz do autor empírico, isto é, que procede diretamente da pessoa que está na origem da produção textual e que intervém para comentar ou avaliar alguns aspectos do que é enunciado; as vozes de personagens, procedentes de seres humanos ou de entidades humanizadas, implicados na qualidade de agentes no percurso temático e, as vozes sociais, ou seja, as vozes de outras pessoas ou instituições humanas mencionadas como instâncias externas de avaliação de alguns aspectos do conteúdo temático do texto (BRONCKART, 1999; 2006).

A partir de qualquer voz enunciativa, podem ser formuladas avaliações sobre alguns elementos do conteúdo temático. Estas avaliações são denominadas de modalizações e são realizadas por unidades ou conjuntos de unidades linguísticas de níveis diferentes, como, por exemplo, através do uso de tempos verbais no futuro do pretérito; auxiliares de modo (poder, ser preciso, ser necessário, dever, querer etc); advérbios ou locuções adverbiais (certamente, provavelmente, evidentemente, talvez, verdadeiramente, sem dúvida, felizmente, infelizmente, obrigatoriamente, deliberadamente etc) e, através de um subconjunto de orações impessoais que regem uma oração subordinada completiva (é provável que, é lamentável que, admite-se geralmente que etc) e de orações adverbiais que regem uma oração completiva (sem dúvida que etc.) (BRONCKART, 1999).

Bronckart $(1999,2006)$ propõe a definição de quatro funções de modalização, baseadas na teoria dos três mundos de Habermas (1989): 
V. 9 (1)

$112-130$

jan-abr

2019

As modalizações lógicas consistem em uma avaliação de alguns elementos do conteúdo temático, apoiada em critérios do mundo objetivo, e apresentam os elementos de seu conteúdo do ponto de vista de suas condições de verdade, como fatos atestados (ou certos), possíveis, prováveis, eventuais, necessários, etc. As modalizações deônticas consistem em uma avaliação de alguns elementos do conteúdo temático, apoiada em valores, opiniões e regras constitutivas do mundo social, apresentando os elementos do conteúdo como sendo do domínio do direito, da obrigação social e/ou da conformidade com as normas em uso.

As modalizações apreciativas consistem em uma avaliação de alguns aspectos do conteúdo temático procedente do mundo subjetivo da voz que é a fonte desse julgamento, apresentandoos como benéficos, infelizes, estranhos, etc., do ponto de vista da entidade avaliadora.

As modalizações pragmáticas contribuem para a explicitação de alguns aspectos da responsabilidade de uma entidade constitutiva do conteúdo temático (personagem, grupo,instituição, etc.) em relação às ações de que é o agente, e atribuem a esse agente intenções, razões (causas, restrições, etc.), ou, ainda, capacidade de ação (BRONCKART, 1999, pp. 330-331).

Levando em conta que a língua é fundamentalmente argumentativa, pois, ao interagirmos, estamos transmitindo nossas ideias e argumentos pretendidos, além da relevância dos mecanismos enunciativos na atuação como indicadores argumentativos, é interessante observarmos suas contribuições na elaboração de um texto argumentativo. Passemos, então, à descrição de aspectos inerentes à proposta de produção de texto dissertativo-argumentativo solicitada anualmente no Exame Nacional do Ensino Médio (Enem). Buscaremos identificar direcionamentos que apontam para a necessidade de utilização dos mecanismos enunciativos, nas competências da matriz de avaliação do Enem.

\section{A proposta de redação do ENEM: competências avaliadas e mecanismos enunciativos na elaboração da argumentação}

Criado em 1998, o Exame Nacional do Ensino Médio (Enem) é utilizado como parte do processo seletivo para o ingresso em Instituições de Ensino Superior públicas e privadas, a partir de uma prova elaborada pelo Ministério da Educação,com o objetivo de verificar o domínio de competências e habilidades dos estudantes que concluíram o ensino médio. O Enem é composto por 180 questões de múltipla escolha, divididas em quatro partes, contemplando as áreas de Linguagens (Português, Literatura, Artes, Educação Física e língua estrangeira) e Ciências Humanas (História, Geografia, Filosofia), Matemática e Ciências 
da Natureza (Biologia, Física e Química). Além das questões de múltipla escolha, o exame é composto por uma proposta de produção textual de caráter dissertativo-argumentativo, sobre um tema selecionado, que pode ser de caráter social, político, científico ou cultural, em que o candidato deve apresentar uma proposta de intervenção que não fira os direitos humanos. O candidato deve obedecer às seguintes competências mencionadas na Cartilha do Participante, disponibilizada no site do Inep (Instituto Nacional de Estudos e Pesquisas Educacionais Anísio Teixeira), para que tenha uma redação avaliada como satisfatória e possa obter a nota máxima (1000):

Quadro 01- Competências avaliadas nas redações do Enem

\begin{tabular}{|l|l|}
\hline Competência 1: & Demonstrar domínio da modalidade escrita formal da língua portuguesa. \\
\hline Competência 2: & $\begin{array}{l}\text { Compreender a proposta de redação e aplicar conceitos das várias áreas de } \\
\text { conhecimento para desenvolver o tema, dentro dos limites estruturais do texto } \\
\text { dissertativo-argumentativo em prosa. }\end{array}$ \\
\hline Competência 3: & $\begin{array}{l}\text { Selecionar, relacionar, organizar e interpretar informações, fatos, opiniões e } \\
\text { argumentos em defesa de um ponto de vista. }\end{array}$ \\
\hline Competência 4: & $\begin{array}{l}\text { Demonstrar conhecimento dos mecanismos linguísticos necessários para a } \\
\text { construção da argumentação. }\end{array}$ \\
\hline
\end{tabular}

Fonte: Redação no Enem 2017. Cartilha do participante².

Daremos destaque às competências 2 , 3 e 5 da matriz de avaliação por serem imprescindíveis ao objetivo deste artigo, ao buscarmos evidenciar a correlação existente entre os usos de mecanismos enunciativos e o que propõe a redação dissertativo-argumentativa do Enem, mais especificamente, através dos aspectos avaliados nas competências destacadas.

A competência 2 destaca que o candidato deve elaborar um texto não apenas expositivo, mas defendendo pontos de vista por meio da argumentação. A cartilha do participante evidencia, nesse sentido, que o texto dissertativo-argumentativo possui dupla natureza, pois, ao mesmo tempo em que é argumentativo, ao defender uma tese, é dissertativo, já que se utiliza

\footnotetext{
Disponível em: <http://download.inep.gov.br/educacao_basica/enem/guia_ participante/2017/manual_de_redacao_do_enem_2017.pdf >. Acesso em 07 de jul. 2018.
} 
V. 9 (1)

$112-130$

jan-abr

2019

de explicações para justificar a tese. Outro aspecto que merece destaque é o de que esta competência exige do candidato a aplicação de conceitos das várias áreas de conhecimento para desenvolver o tema. Assim, quanto mais o candidato demonstrar em seu texto conhecimentos de várias áreas, mais ele estará utilizando estratégias argumentativas para convencer o leitor, o que é considerado pela banca avaliadora como um "repertório sociocultural produtivo". Estes aspectos estão relacionados com as vozes enunciativas apresentadas por Bronckart (1999; 2006), já que o produtor do texto poderá evidenciar em seu texto sua própria voz (vozes do autor empírico), vozes sociais ou vozes de personagens, conforme for desenvolvendo argumentações consistentes e aplicando o seu repertório sociocultural. Vale salientar que as modalizações explicitadas pelo mesmo autor também colaboram para a posição e discurso do produtor do texto, com a manifestação de colocações consistentes e seguras em relação ao tema.

A competência 3 possui semelhanças com a competência anteriormente mencionada, já que enfatiza a necessidade de elaborar um texto em que conste uma ideia a ser defendida e os argumentos para justificar a posição assumida pelo candidato no que diz respeito à temática da redação. O enfoque principal, no entanto, é o de avaliar a coerência textual, de modo que o leitor possa interpretar os sentidos do texto e atue aceitando, recusando ou questionando as ideias e opiniões contidas no texto. Dessa forma, ao "Selecionar, relacionar, organizar e interpretar informações, fatos, opiniões e argumentos em defesa de um ponto de vista", o candidato também fará uso das modalizações.

Quanto à competência 5, podemos salientar que, ao expressar possíveis soluções para o problema discutido, sem desrespeitar os direitos humanos, de imediato, já identificamos direcionamentos para o mundo social (HABERMAS, 1989), pois deverão preponderar os valores de cidadania, liberdade, solidariedade e diversidade cultural na proposta de intervenção a ser elaborada, decorrentes do compartilhamento e aceitação de condutas sociais. Além disso, o candidato deve mencionar atores sociais que sejam competentes para executar a sua proposta de intervenção, assim, consideramos que nesta etapa do texto haverá a predominância de modalizações pragmáticas, ao consistirem na explicitação de aspectos da responsabilidade de uma entidade constitutiva do conteúdo temático em relação às ações de que é o agente, atribuindo a ele intenções, razões, ou ainda, capacidades de ação (BRONCKART, 1999; 2006), o que irá demonstrar sua relevância na construção do texto dissertativo-argumentativo indicado pelo Enem. 
Passemos, agora, à análise de algumas redações que obtiveram nota máxima no Enem de 2017, de modo a verificar a correlação dos mecanismos enunciativos e a elaboração de um texto dissertativoargumentativo que atenda aos critérios avaliados pelo Exame.

\section{Os mecanismos enunciativos nas produções textuais dissertativo- argumentativas do Enem 2017}

A proposta de produção textual dissertativo-argumentativa do Enem no ano de 2017 teve como tema "Desafios para a formação educacional de surdos no Brasil". Dentre as 53 redações que obtiveram nota mil, selecionamos 4 delas com o intuito de verificarmos a relevância dos mecanismos enunciativos para a elaboração de um texto dissertativo-argumentativo que atenda aos critérios de correção estabelecidos pelo Enem, através da presença de vozes e modalizações. Procedamos à análise das redações.

Os fragmentos das redações ${ }^{3}$, a seguir, demonstram a verificação dos usos de modalizações:

(1) No Brasil, o início do processo de educação de surdos remonta ao Segundo Reinado. No entanto, esse ato não se configurou como inclusivo, já que se caracterizou pelo estabelecimento de um "apartheid" educacional, ou seja, uma escola exclusiva para tal público, segregando-o dos que seriam considerados "normais" pela população. Assim, notam-se desafios ligados à formação educacional das pessoas com dificuldade auditiva, seja por estereotipação da sociedade civil, seja por passividade governamental. Portanto, haja vista que a educação é fundamental para o desenvolvimento econômico do referido público e, logo, da nação, ela deve ser efetivada aos surdos pelos agentes adequados, a partir da resolução dos entraves vinculados a ela. (R1)

O candidato que elaborou a redação R1 introduz a tese de que, apesar de, durante o Segundo Reinado, o processo de educação dos surdos ter se iniciado, a consequente e contínua segregação dos

3 Embora a autoria das redações tenha sido divulgada amplamente, optamos por identificar os fragmentos através das denominações R1, R2, R3 e R4, respectivamente. As redações não estão na íntegra, tendo em vista que buscamos dar ênfase aos mecanismos enunciativos nelas encontrados. 
V. 9 (1)

$112-130$

jan-abr

2019

surdos demonstra que os desafios para sua formação educacional estão relacionados a uma estereotipação da sociedade e à passividade do Governo, sendo a educação inclusiva fundamental para a resolução dessa problemática. Em (01), observamos que "notam-se" se configura como modalização lógica, ao fazer referência a um fato atestado e certo (BRONCKART, 1999; 2006), isto é, o de existirem "desafios ligados à formação educacional das pessoas com dificuldade auditiva, seja por estereotipação da sociedade civil, seja por passividade governamental". Em "é fundamental", identificamos uma modalização pragmática, concernente ao fato de que é a partir da educação que nós podemos nos desenvolver economicamente. A educação é responsável pelo crescimento econômico dos indivíduos, tornando-se, portanto, algo fundamental. Apoiando-se nas representações constitutivas do mundo social, elucidadas por Bronckart (1999; 2006), o candidato faz uso da modalização deôntica "deve ser", denotando a obrigação de agentes sociais intervirem na busca de soluções acerca da problemática da segregação dos surdos na educação.

O fragmento 02 ilustra alguns dos argumentos apontados na R1 pelo candidato, na busca de desenvolver justificativas para comprovar a sua tese:

(2) Sob esse viés, pode-se apontar como um empecilho à implementação desse direito, reconhecido por mecanismos legais, a discriminação enraizada em parte da sociedade, inclusive dos próprios responsáveis por essas pessoas com limitação. Isso por ser explicado segundo o sociólogo Talcott Parsons, o qual diz que a família é uma máquina que produz personalidades humanas, o que legitima a ideia de que o preconceito por parte de muitos pais dificulta o acesso à educação pelos surdos. Tal estereótipo está associado a uma possível invalidez da pessoa com deficiência e é procrastinado, infelizmente, desde o Período Clássico grego, em que deficientes eram deixados para morrer por serem tratados como insignificantes, o que dificulta, ainda hoje, seu pleno desenvolvimento e sua autonomia. (R1)

Ao utilizar "pode-se apontar", o candidato justifica como uma razão da dificuldade de implementação do direito dos surdos à educação, a discriminação dos surdos por parte da sociedade e da própria esfera familiar, o que indica o termo como uma modalização pragmática. Posteriormente, identificamos o uso da modalização apreciativa "infelizmente", asseverado por Bronckart (1999; 2006) 
como procedente do mundo subjetivo do ponto de vista da entidade avaliadora, a pessoa que produziu o texto, apresentando o fato de, desde o Período Clássico existir a ideia de que os surdos são considerados "inválidos", como algo negativo e maléfico.

(3) Diante do exposto, cabe às instituições de ensino com proatividade o papel de deliberar acerca dessa limitação em palestras elucidativas por meio de exemplos em obras literárias, dados estatísticos e depoimentos de pessoas envolvidas com o tema, para que a sociedade civil, em especial os pais de surdos, não seja complacente com a cultura de estereótipos e preconceitos difundidos socialmente. Outrossim, o próprio público deficiente deve alertar a outra parte da população sobre seus direitos e suas possibilidades no Estado civil a partir da realização de dias de conscientização na urbe e da divulgação de textos proativos em páginas virtuais, como "Quebrando o Tabu". Por fim, ativistas políticos devem realizar mutirões no Ministério ou na Secretaria de Educação, pressionando os demiurgos indiferentes à problemática abordada, com o fito de incentivá-los a profissionalizarem adequadamente os professores - para que todos saibam, no mínimo, o básico de Libras - e a efetivarem o estudo da Língua Brasileira de Sinais, por meio da disponibilização de verbas e da criação de políticas públicas convenientes, contrariando a teórica inclusão da primeira escola de surdos brasileira. (R1)

Em (03), ao formular a sua proposta de intervenção, que, conforme já foi enfatizado, possui caráter fortemente pragmático, o candidato utiliza modalizações pragmáticas como "deve alertar" e "devem realizar". Tendo em vista que a proposta de intervenção solicitada pelo Enem está associada a atitudes a serem tomadas por agentes sociais, a avaliação feita pelo candidato está pautada em responsabilidades de entidades (destes agentes sociais) sendo a eles atribuídas capacidades de ação, como o próprio público deficiente alertar a população sobre seus direitos e os ativistas políticos realizarem mutirões a fim de incentivar o Ministério ou na Secretaria de Educação a criarem cursos profissionalizantes de Libras para os professores.

O fragmento 04 atesta os usos de modalizações em alguns dos argumentos expostos na $\mathrm{R} 2$ : 
v. 9 (1)

$112-130$

jan-abr

2019

(4) A formação educacional de surdos encontra, no Brasil, uma série de empecilhos. Essa tese pode ser comprovada por meio de dados divulgados pelo Inep, os quais apontam que o número de surdos matriculados em instituições de educação básica tem diminuído ao longo dos últimos anos. Nesse sentido, algo deve ser feito para alterar essa situação, uma vez que milhares de surdos de todo o país têm o seu direito à educação vilipendiado, confrontando, portanto, a Constituição Cidadã de 1988, que assegura a educação como um direito social de todo o cidadão brasileiro. (R2)

Para sustentar a tese de que a formação educacional dos surdos no Brasil encontra empecilhos, o candidato usa a locução verbal "pode ser", que configura como uma modalização lógica ao mencionar os dados divulgados pelo Inep como um dos meios que comprovam sua tese. Em seguida, a locução verbal "deve ser", presente no fragmento, se configura como uma modalização pragmática, uma vez que ressalta a responsabilidade de entidades para que algo seja feito porque "milhares de surdos de todo o país têm o seu direito à educação vilipendiado".

A modalização lógica se faz presente em (05), ao expor a proposta de intervenção da R2:

(5) (...) Outrossim, ONGs devem promover, através da mídia, campanhas que conscientizem a população acerca da importância do deficiente auditivo para a sociedade, enfatizando em mostrar a capacidade cognitiva e intelectual do surdo, o qual seria capaz de participar da população economicamente ativa (PEA), como fosse concedido a este o direito à educação e à equidade de tratamento, por meio da difusão do uso de libras. Dessa forma, o Brasil poderia superar os desafios à consolidação da formação educacional de surdos. (R2)

Inicialmente, para mencionar a responsabilidade das ONGs de conscientizarem a população "acerca da importância do deficiente auditivo para a sociedade, enfatizando em mostrar a capacidade cognitiva e intelectual do surdo", o candidato utiliza a modalização pragmática "devem promover". Em seguida, para ratificar a atuação das ONGs como uma condição e possibilidade para o Brasil "superar os 
desafios à consolidação da formação educacional de surdos", verificamos o uso do verbo condicional "poder". Tal constatação corrobora com a afirmação de Bronckart (1999) de que as modalizações lógicas podem ser traduzidas pelos tempos verbais do condicional.

Em (06) e (07) observamos a presença de modalizações na R3, na menção de argumentos para sustentar o que é defendido e na elaboração da proposta de intervenção, respectivamente:

(6) (...) Vale ressaltar, também, que a exclusão vivenciada por deficientes auditivos no país evidencia práticas históricas de preconceito. A respeito disso, sabe-se que, durante o século XIX, a ciência criou o conceito de determinismo biológico, utilizado para legitimar o discurso preconceituoso de inferioridade de grupos minoritários, segundo o qual a função social do indivíduo é determinada por características biológicas. (R3)

(7) É evidente, portanto, que há entraves para que os deficientes auditivos tenham pleno acesso à educação no Brasil. Dessa maneira, é preciso que o Estado brasileiro promova melhorias no sistema público de ensino do país, por meio de sua adaptação às necessidades dos surdos, como oferta do ensino de libras, com profissionais especializados para que esse grupo tenha seus direitos respeitados (...). (R3)

O uso de "sabe-se que", em (06), traduz uma modalização lógica a respeito de um fato atestado, isto é, o de que "a ciência criou o conceito de determinismo biológico, utilizado para legitimar o discurso preconceituoso de inferioridade de grupos minoritários, segundo o qual a função social do indivíduo é determinada por características biológicas". Em (07), percebemos o uso da estrutura oracional "é evidente" também como modalização lógica a respeito de algo comprovado, ou seja, "que há entraves para que os deficientes auditivos tenham pleno acesso à educação no Brasil". Devido a isso, o candidato expõe como proposta de intervenção a responsabilidade do Estado de promover melhorias no sistema público de ensino, utilizando a estrutura oracional "é preciso que", que traduz uma modalização pragmática, ao estar apoiada em capacidades de ação do agente Estado.

O fragmento (08) destaca as modalizações presentes na tese e argumentos da $\mathrm{R}_{4}$ : 
V. 9 (1)

112-130

jan-abr

2019

126
(8) Sob a perspectiva filosófica de São Tomás de Aquino, todos os indivíduos de uma sociedade democrática possuem a mesma importância, além dos mesmos direitos e deveres. No entanto, percebe-se que, no Brasil, os deficientes auditivos compõem um grupo altamente desfavorecido no tocante ao processo de formação educacional, visto que o país enfrenta uma série de desafios para atender a essa demanda. Nesse contexto, torna-se evidente a carência de estrutura especializada no acompanhamento desse público, bem como a compreensão deturpada da função social deste.

O filósofo italiano Norberto Bobbio afirma que a dignidade humana é uma qualidade intrínseca ao homem, capaz de lhe dar direito ao respeito e à consideração por parte do Estado. Nessa lógica, é notável que o poder público não cumpre o seu papel enquanto agente fornecedor de direitos mínimos, uma vez que não proporciona aos surdos o acesso à educação com qualidade devida, o que caracteriza um irrespeito descomunal a esse público. A lamentável condição de vulnerabilidade à qual são submetidos os deficientes auditivos é percebida no déficit deixado pelo sistema educacional vigente no país, que revela o despreparo da rede de ensino no que tange à inclusão dessa camada, de modo a causar entraves à formação desses indivíduos e, por conseguinte, sua inserção no mercado de trabalho. (R4)

Observamos uma preponderância do uso de termos que funcionam como modalizações lógicas, ao serem citados fatos atestados. O uso de "percebe-se que" assegura a tese de que "os deficientes auditivos compõem um grupo altamente desfavorecido no tocante ao processo de formação educacional"; a utilização de "tornase evidente" demonstra como consequência desta tese que há "carência de estrutura especializada no acompanhamento desse público, bem como a compreensão deturpada da função social deste". Por sua vez, a modalização lógica traduzida pelo uso do segmento "Nessa lógica, é notável que" retoma o fato de que o Poder Público não cumpre com o papel de fornecer direitos mínimos, como a própria dignidade humana, princípio intrínseco ao homem, conforme afirmação feita por Bobbio. 
Essas explicações reforçam a tese apresentada pelo candidato. Por fim, salientamos que o uso de "lamentável" referindo-se à condição de vulnerabilidade dos deficientes auditivos, que se configura como uma modalização apreciativa, já que a condição de vulnerabilidade é avaliada como negativo e infeliz, do ponto de vista da entidade avaliadora (a pessoa que produziu o texto).

Em (09), observamos o uso da estrutura oracional "é necessário que":

(9) (...) Logo, é necessário que o Ministério da Educação, em parceria com instituições de apoio ao surdo, proporcione a este maiores chances de se inserir no mercado, mediante a implementação do suporte adequado para a formação escolar e acadêmica desse indivíduo - com profissionais especializados em atende-lo -, a fim de gerar maior igualdade na qualificação e na disputa por emprego (...). (R4)

Assim como foi constatado nas redações anteriores, ao propor uma intervenção, os candidatos fazem uso de estruturas que denotam a modalização pragmática, tal como ocorre em (09), através da estrutura oracional "é necessário que". A predominância destas modalizações nesta seção que compõe a estrutura do dissertativoargumentativo do Enem diz respeito ao caráter propositivo inerente aos próprios critérios de análise, ao considerar que o participante deve indicar agentes/atores sociais para buscar soluções, elencando meios e efeitos da ação indicada.

Passemos, agora, à análise das instâncias enunciativas nas redações, de modo a asseverar a relevância do gerenciamento de vozes para a construção do texto dissertativo-argumentativo proposto pelo Enem. Levando em conta que é inerente ao texto dissertativoargumentativo a presença da voz do autor, uma vez que o produtor textual atua diretamente para avaliar aspectos os quais ele enuncia (BRONCKART, 1999), concretizados, como vimos, através do uso das modalizações, os fragmentos seguintes elucidam a presença de outras vozes, juntamente à voz do autor: 
V. 9 (1)

$112-130$

jan-abr

2019

(10) Sob esse viés, pode-se apontar como um empecilho à implementação desse direito, reconhecido por mecanismos legais, a discriminação enraizada em parte da sociedade, inclusive dos próprios responsáveis por essas pessoas com limitação. Isso por ser explicado segundo o sociólogo Talcott Parsons, o qual diz que a família é uma máquina que produz personalidades humanas, o que legitima a ideia de que o preconceito por parte de muitos pais dificulta o acesso à educação pelos surdos. (...) (R1)

(11) Sob a perspectiva filosófica de São Tomás de Aquino, todos os indivíduos de uma sociedade democrática possuem a mesma importância, além dos mesmos direitos e deveres. No entanto, percebe-se que, no Brasil, os deficientes auditivos compõem um grupo altamente desfavorecido no tocante ao processo de formação educacional, visto que o país enfrenta uma série de desafios para atender a essa demanda. Nesse contexto, torna-se evidente a carência de estrutura especializada no acompanhamento desse público, bem como a compreensão deturpada da função social deste. o filósofo italiano Norberto Bobbio afirma que a dignidade humana é uma qualidade intrínseca ao homem, capaz de lhe dar direito ao respeito e à consideração por parte do Estado. Nessa lógica, é notável que o poder público não cumpre o seu papel enquanto agente fornecedor de direitos mínimos, uma vez que não proporciona aos surdos o acesso à educação com qualidade devida, o que caracteriza um irrespeito descomunal a esse público (...). (R4)

Para melhor explicar que a discriminação aos surdos advém, muitas vezes, da própria entidade familiar, o participante explicita em seu texto, (10), a voz do sociólogo Talcott Parsons. Conforme Bronckart (1999; 2006) expõe, trata-se de uma voz de personagem, já que procede de um ser humano, implicado, na qualidade de agente, na ação constitutiva do conteúdo temático deste segmento do texto.

Do mesmo modo, em (11), observamos as vozes de personagens através dos discursos dos filósofos São Tomás de Aquino e Norberto Bobbio, que asseveram o fato de que todo homem possui direitos essenciais, como a educação, e, portanto, cabe ao Estado fornecer esse direito mínimo aos indivíduos surdos. 
Diferentemente, em (12), é evidenciada uma voz social:

(12)(...) Vale ressaltar, também, que a exclusão vivenciada por deficientes auditivos no país evidencia práticas históricas de preconceito. A respeito disso, sabe-se que, durante o século XIX, a ciência criou o conceito de determinismo biológico, utilizado para legitimar o discurso preconceituoso de inferioridade de grupos minoritários, segundo o qual a função social do indivíduo é determinada por características biológicas. (R3)

Para sustentar se ainda hoje há a presença do discurso científico de que a função social do indivíduo é consequência de suas características biológicas, o que colabora para a permanência da situação de preconceito vivenciada pelos indivíduos surdos, o participante cita a instância científica e sua criação do conceito de determinismo biológico, o que se configura como uma voz social. De acordo com as ideias de Bronckart (1999; 2006), neste caso, esta instituição social não intervém diretamente, como em (10) e (11), como agente no percurso temático do texto, mas é mencionada como instância externa de avaliação de aspectos deste conteúdo.

Estes "discursos do outro", presentes nos fragmentos acima, demonstram a polifonia apontada nos estudos desenvolvidos por Bakhtin (2006). Além disso, funcionam como estratégias argumentativas para convencer o leitor, reforçando o "repertório sociocultural produtivo" do participante, mencionado na cartilha do Enem, sendo, portanto, sua presença essencial nas redações do Enem.

\section{Considerações Finais}

No presente artigo, analisamos a correlação dos mecanismos enunciativos (vozes e modalizações) e a proposta de produção textual do Enem, apontando sua relevância para a elaboração de uma redação dissertativo-argumentativa satisfatória, com base na identificação de direcionamentos destes mecanismos em competências da matriz de avaliação do Exame e na verificação da presença de vozes e modalizações em algumas produções textuais de 2017 que obtiveram nota máxima. Verificamos a presença das modalizações lógica, deôntica, apreciativa e pragmática nas produções selecionadas, reforçando sua importância 
V. 9 (1) $112-130$ jan-abr 2019

para uma produção textual que atenda aos critérios avaliados pelo Enem. Demos ênfase ao fato de que, mais especificamente, na seção em que o participante escrevia uma proposta de intervenção, exigida na matriz de avaliação, com base na competência 5, houve predominância das modalizações pragmáticas. Tal constatação se justificou pelo caráter propositivo de responsabilidades atribuídas a entidades/agentes sociais, inerente ao que é exigido na matriz de avaliação.

Por fim, explicitamos as instâncias enunciativas presentes nas redações, através do gerenciamento das vozes do autor, de personagem e sociais. Ratificamos sua contribuição ao funcionar como "estratégias argumentativas" para convencer o leitor, reforçando o "repertório sociocultural produtivo" do participante.

\section{Referências}

BAKHTIN, Mikhail. Marxismo e filosofia da linguagem. São Paulo: Hucitec, 2006.

BRONCKART, Jean-Paul. Atividade de linguagem, textos e discursos. São Paulo: Educ, 1999.

Atividade de linguagem, discurso e desenvolvimento humano.

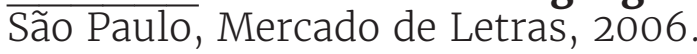

FARACO, Carlos Alberto. A relevância social da linguística: linguagem, teoria e ensino. São Paulo: Parábola editoria; Ponta Grossa, PR: UEPG, 2007.

FIORIN, José Luiz. Introdução ao pensamento de Bakhtin. São Paulo: Ática, 2006.

HABERMAS, Jürgen. Consciência moral e agir comunicativo. Rio de Janeiro: Tempo Brasileiro, 1989.

MARCUSCHI, Luiz Antônio. Produção textual, análise de gêneros e compreensão. 3. ed. São Paulo: Parábola, 2009.

Gêneros textuais: definição e funcionalidade. In: DIONíSIO, Angela et al. (orgs.). Gêneros textuais e ensino. Rio de Janeiro: Lucerna, 2010. p. 1938.

Redação no Enem 2017. Cartilha do participante. Disponível em: <http:// download.inep.gov.br/educacao basica/enem/guia participante/2017/ manual de redacao do enem 2017.pdf $>$. Acesso em 07 de jul. 2018.

VYGOTSKY, Lev Semyonovitch. A formação social da mente. São Paulo, Martins Fontes, 1984 [1930].

Disponível em <https://enem.inep.gov.br/participante/>. Acesso em o7 de jul. 2018. 